\title{
THE SITUATION AND EFFICIENCY OF USING E-LEARNING TRAINING MODEL AT CAN THO UNIVERSITY
}

\section{Tam Phuong Pham ${ }^{+}$, Tan Minh Nguyen}

\author{
Article History \\ Received: January 17,2020 \\ Accepted: February 26, 2020 \\ Published: March 30, 2020 \\ Keywords \\ Training, E-learning, \\ Mekong Delta Region, \\ Can Tho University
}

\author{
Can Tho University, Vietnam \\ +Corresponding author •Email: pptam@ctu.edu.vn
}

\section{INTRODUCTION}

With the global development trend in education, it is crucial to promote the application of information and communication technologies in distance teaching and learning methods such as E-learning to fully exploit personal information and communication devices in learning. In order to fully support lecturers' teaching activities and students' learning and self-study activities, it is necessary to invest and apply these methods quickly and effectively as they are both the responsibility and obligation of higher education institutions.

Meeting the mentioned requirements, Can Tho University has been making tremendous efforts to invest in upgrading the information technology system in parallel with enhancing E-learning application in distance learning activities of the university. This confirms the right direction of the development trend of the world and the country in general and is suitable with the conditions and characteristics of the Mekong Delta region in particular in order to diversify forms of training, develop new educational forms and create many more opportunities and conditions for learners in the context of comprehensive modernization of education and training in Vietnam nowadays.

\section{LITERATURE REVIEW}

In the history of Vietnamese and international education and training development, there have been many authors and research works related to the role and advantages of E-learning in training and developing human resources. In the early years of the $21^{\text {st }}$ century, there were a number of research authors who studied and summarized E-learning experience in training and considered it the new learning trend of the era and a popular learning method in the future because of its merits in academic society. Alias and Zainuddin (2005) mentioned the trend of educational innovation in applying learning management system (LMS). In the same year, Alonso, López and Vines (2005) drafted a set of rules for the E-learning model on web-based platforms applied to mixed training.

In the era of the forth Industrial Revolution, learning conditions and methods are becoming more and more diverse and online learning is also becoming more and more popular. In that context, Annika (2009) introduced the concept of E-learning development platform in developing countries. In addition to the research of international scientists, in Vietnam, Tran Thanh Dien and Nguyen Thai Nghe (2017) also conducted research works on E-learning models facilitating teaching and learning in specific conditions at Can Tho University. Nguyen Ngoc Trang (2017) mentioned some research results on this issue in her doctoral thesis. The above studies have contributed to clarify the theoretical basis for the implementation of E-learning in the world and in Vietnam; factors of concern and elements that ensure the systemization and quality of E-learning.

From the aforementioned studies, it can be generalized that E-learning has gained tremendous interests from both domestic and international scientists in research and application in the educational development worldwide. However, the issue of E-learning training in Vietnam has not been popular, so these theoretical bases when applying to specific cases are still open for further studies. In this article, we will continue our research to further clarify E-learning in Vietnam through practical implementation at Can Tho University.

\section{METHODOS AND RESULTS}

\subsection{Research methods}


The researchers used descriptive method to explore the perception level of different target groups such as management staff, lecturers and students and factors affecting the implementation as well as the effectiveness of Elearning in Vietnam through evaluating the effectiveness of E-learning at Can Tho University. The use of descriptive research methods helps illustrate and explain the situation of the study. In this study, it is used to describe the level of perception of E-learning and factors affecting the implementation of E-learning at Can Tho University.

The research tool used in this article is a Likert scale questionnaire with three parts including personal information, the perception level of E-learning of the survey participants and factors affecting the implementation process of E-learning at Can Tho University.

The collected data is described statistically, using percentages and mean for the perception level of the above subjects on E-learning, and initially identifies factors affecting the implementation of E-learning in Vietnam.

\subsection{Definition of E-learning}

According to researchers, there are numerous viewpoints, explanations or definitions by scientists, managers and trainers of E-learning. E-learning can be understood simply as effectively applying technology, advances in science and technology to participate in classrooms outside the traditional physical ones. In most cases, it involves training courses, programs or certificates which are entirely online (Pham Phuong Tam, 2017).

Some experts also state that E-learning is a new method of education and training, a revolution in education of the $21^{\text {st }}$ century with the application of high technology to provide training services and courses through the Internet or support the learning process of learners. E-learning is a form of training assisted by the application of information and communication technology; or in other words, the application of electronic means in the process of teaching and learning, including spatial and temporal gaps.

The most widely acknowledged concept is that E-learning is a combination of face-to-face training and online teaching. Just like face-to-face training, students will meet teachers through the World Wide Web platform and interact with lecturers via the Internet, similar to going to class.

The outstanding advantage of E-learning compared to traditional educational methods is the creation of an open learning environment and the reuse of learners. With this technology, the process of teaching and learning will be more efficient and faster, helping to reduce about $60 \%$ of the cost, while reducing $20-40 \%$ of training time compared to traditional teaching methods. The difference between E-learning in Vietnam and that in the world is that higher education institutions recognize E-learning as a form of Internet-based training and student access to the E- learning system of training institutions to learn through the provided learning materials (Bui Thanh Giang, 2004).

In addition, this form of training also has many advantages such as the flexibility in organizing and managing the training process, allowing learners to study at any time and place. As learners can proactively choose to learn necessary contents, modules, materials, it will create excitement as well as increase the initiative and activeness of learners in the process of acquiring knowledge. At the same time, E-learning helps learners save large travel \& printing costs throughout the learning process. Higher education institutions also take advantage of facilities, teaching staff, management staff, training programs as well as the learning materials system.

\subsection{The viewpoint of Can Tho University on the application of E-learning in distance training}

The Declaration on the Mission of Can Tho University states that it is a multi-disciplinary university that focuses on undergraduate and postgraduate training, scientific research and technology transfer, contributing to the economic, social and cultural development progress in the Mekong Delta. Therefore, to carry out the above mission, the University is consistent with the efforts to utilize and maximize the available resources of teaching staff, learning materials, facilities, equipment,... to meet the practical needs of training high-quality human resources for the "take off" of the Mekong Delta, adapting to the fourth industrial revolution.

Along with formal training, distance training has also been implemented and organized by Can Tho University. In the progress of implementation, Can Tho University is committed to quality assurance in compliance with the regulations of the Ministry of Education and Training set out for all forms of university-level training available at the university. The university always determines that distance learning has the equal mission, role and meaning as those of other forms of training in all stages from organization, management and training quality assurance, contributing greatly to the training of high quality human resources to meet development needs of the region and country, in line with the policy of building a learning society, lifelong learning and minimizing the geographical imbalance in accessing education. 
In the next step, Can Tho University also has many guidelines and determination to implement E-learning applications in the training programs offered, especially in distance training, creating opportunities and conditions for learners, especially those participating in distance training.

In the general development process of the university, as a form of distance training with the application of information technology, E-learning has contributed greatly to the training and quality improvement, which is a significant achievement for a higher education institution.

\subsection{The reality of E-learning application at Can Tho University}

The fourth Industrial Revolution results in the improvement of methods of management, administration, etc. through the boost in the application of information technology utilities. Education is no exception, as textbooks, materials as well as lectures are gradually digitized, replacing traditional printed paper materials. Following the trend, Can Tho University has been digitizing available resources for its distance learning process.

Currently, Can Tho University owns a Learning Resource Center with its own Internet connection, a bandwidth of about $75 \mathrm{Mbps}$ internationally and $150 \mathrm{Mbps}$ domestically, connecting to most units such as faculties, institutes, centers, departments, classrooms, etc. to respond quickly and effectively to information access for nearly 2,600 staff and about 65,000 students of various trainings including distance training. Server room is built for integrated information systems and other services such as website, email, E-learning. Especially, Can Tho University has invested in more than 1,000 public computers and wifi system covered throughout the campus for free access to students. The university also provides computer login accounts so students can access the school's digital material system with an amount of about 30,000 documents in different languages.

In terms of E-learning, from a very early stage, Can Tho University has invested in building and operating an Elearning application system to support online teaching and learning (also called E-learning system) and Learning Management System (LMS) to fully serve the purposes of teaching and learning, self-study activities with a system of lectures and teaching materials provided to students through the system. Besides, the university also records lectures of lecturers to compile and upload them to the university's servers so that students can access for reference. Testing and evaluation through the system are also soon to be implemented.

To evaluate the initial results of the implementation, Can Tho University conducted a survey on the subjects related to the above activities including students (342 students), lecturers (59 lecturers) and management staff (26 employees) on a 4-level scale: Weak/ Average/ Fair/ Good. A summary of some evaluation of the subjects reveals the following results:

\subsubsection{Evaluation of students}

In terms of E-learning, the contents of teaching and the amount of knowledge almost had no effect when this audience evaluated the content. The content of lectures is highly appreciated with over $55 \%$ of the comments being good. In addition, four out of the remaining five aspects had very high positive ratings (over 40\%) and the other two aspects, the level of interaction and the content of the level of support were rated as good by $48.8 \%$ and $49.6 \%$ of students. Thereby, it can be seen that for students participating in the survey, E-learning has grown along with the development of information technology infrastructure to meet the needs of updating and supplementing knowledge as with face-to-face class, but more conveniently because it is all performed via the Internet.

However, an equally important content, which is the ability of students to participate in the class, achieved a not so good assessment (only 19.7\% good) with a weak assessment rate of up to $26.1 \%$. It can be seen that despite meeting the requirements of providing knowledge, E-learning is still limited in terms of performance and access to classrooms due to the relatively low level of information technology skills of students.

\subsubsection{Evaluation of lecturers}

As for lecturers, this group also confirms that learners are still not proficient and make ineffective use of online learning due to the limited level of information technology skills. The Internet transmission system still has many problems that make it difficult for the training process. This can be seen in the chart below when students' ability to participate in class was also rated extremely low by this group, with the good, fair and weak levels being at $11.9 \%$, $10.2 \%$ and $55.9 \%$ respectively. Another aspect that did not really satisfy the lecturers was the interaction rate when only $32.3 \%$ of lecturers gave the positive comment and $22 \%$ weak performance. The figures show that teachers still "prefer" the traditional face-to-face methods though the other statements were highly appreciated by this group. In particular, around $50 \%$ of the lecturers commented that the level of knowledge transfer, content of lectures, support rate as well as IT Infrastructure all had a good performance - 3 of these 4 aspects achieved over $50 \%$ as positive result. 


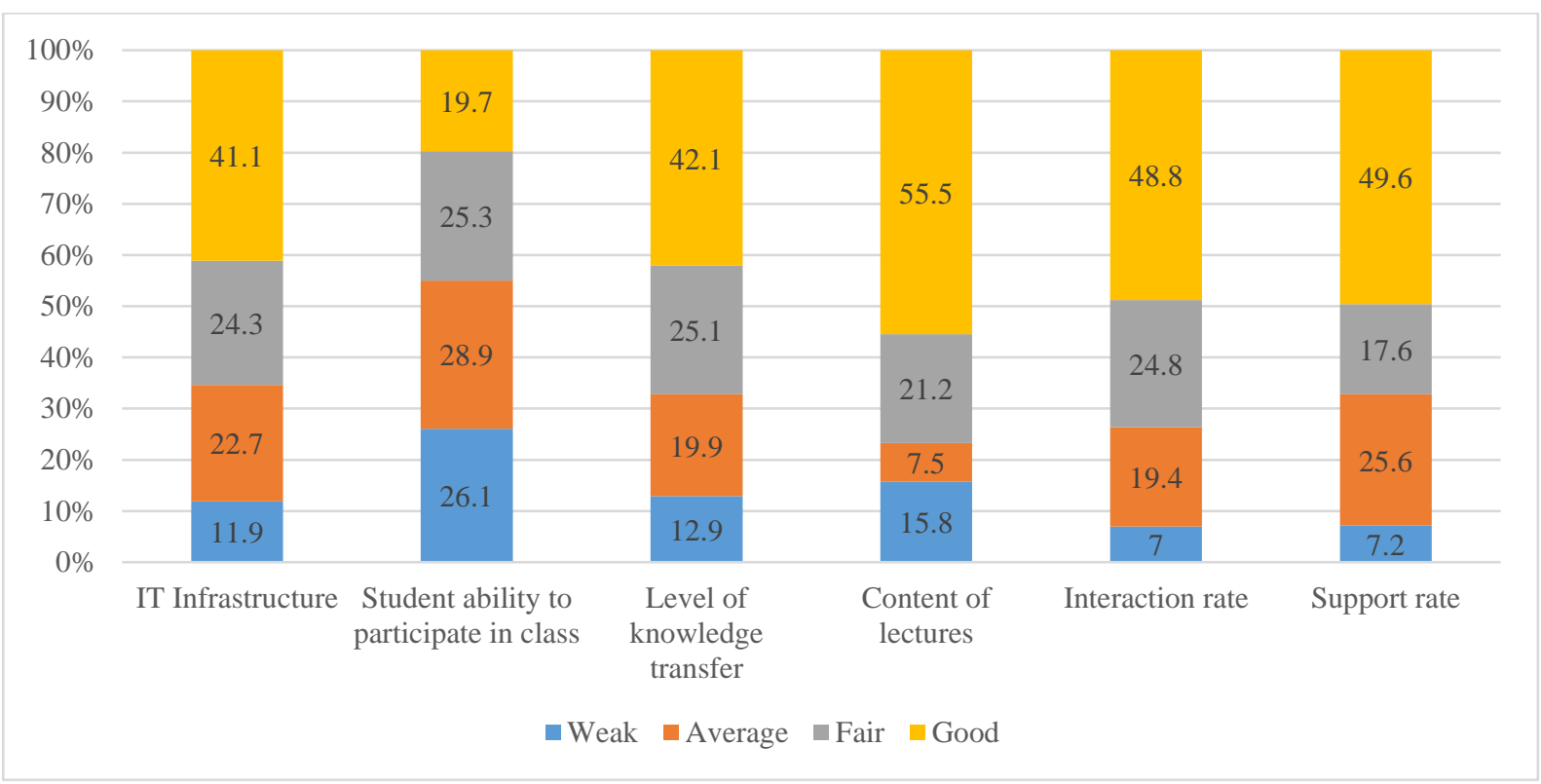

Figure 1. Evaluation of students when using E-learning for learning activities

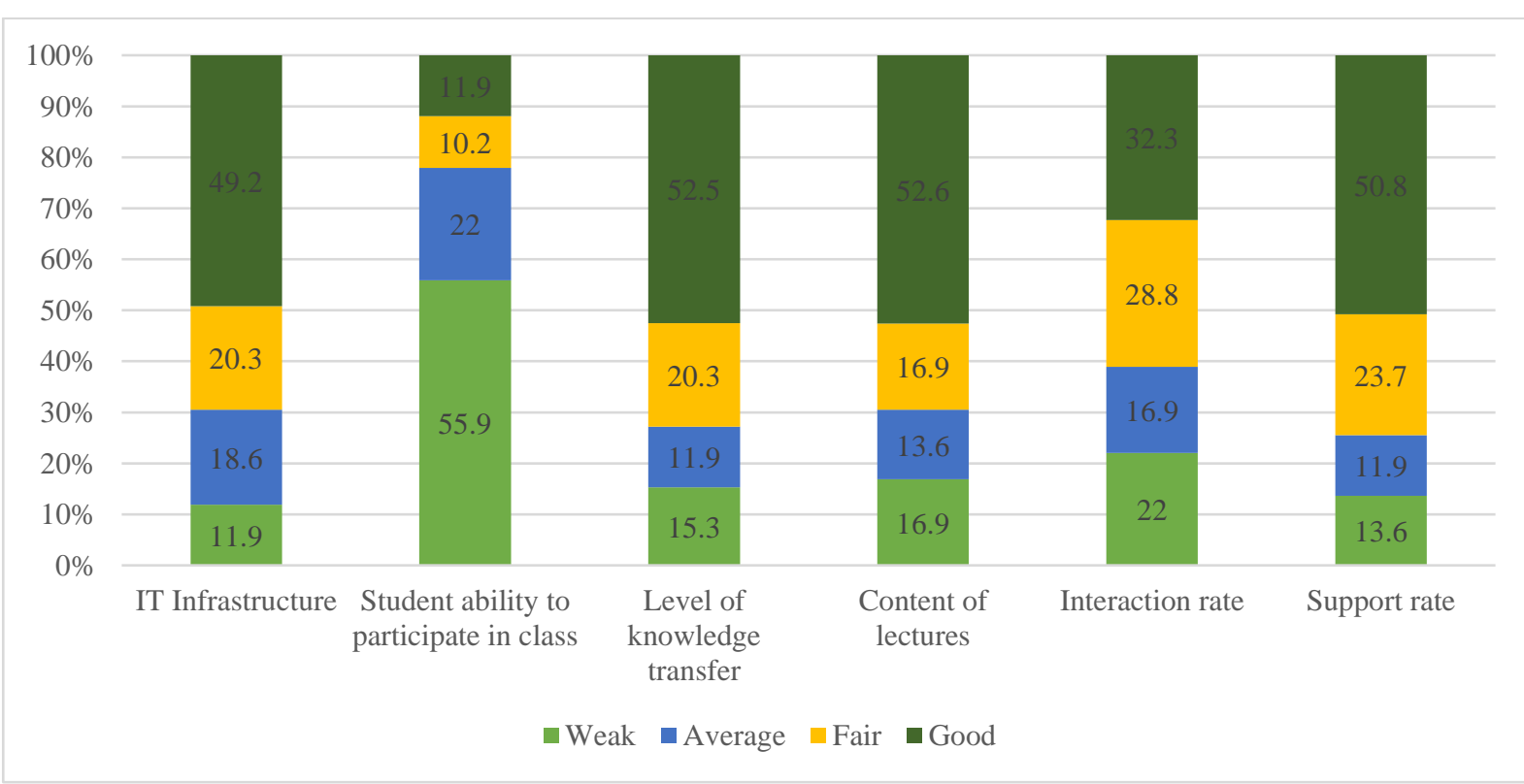

Figure 2. Evaluation of lecturers when using E-learning for teaching activities

\subsubsection{Evaluation of management staff}

As for management staff, E-learning has only one obstacle which is the students' ability to participate in class. This group had the same comments as the teaching staff when evaluating this aspect, with the weak rating accounting for the highest proportion at $23.1 \%$ and the final results was also compiled as positive feedbacks for this content. Accordingly, it can be realized that for management staff, this limitation can be overcome to continue to develop E-learning.

In the opposite direction, the management team considered the content of lectures in E-learning very good given that the good rating for this aspect accounts for up to $46.2 \%$ and there was no positive rating. Along with that, the feedback concerning knowledge transfer was also very positive with only $11.5 \%$ for weak assessment rate while the good and fair assessment rate accounted for $34.7 \%$ and $42.3 \%$ respectively. Thereby, it can be seen that the development potential of E-learning, when the knowledge transmitted is recognized, is not inferior to the traditional face-to-face method. 


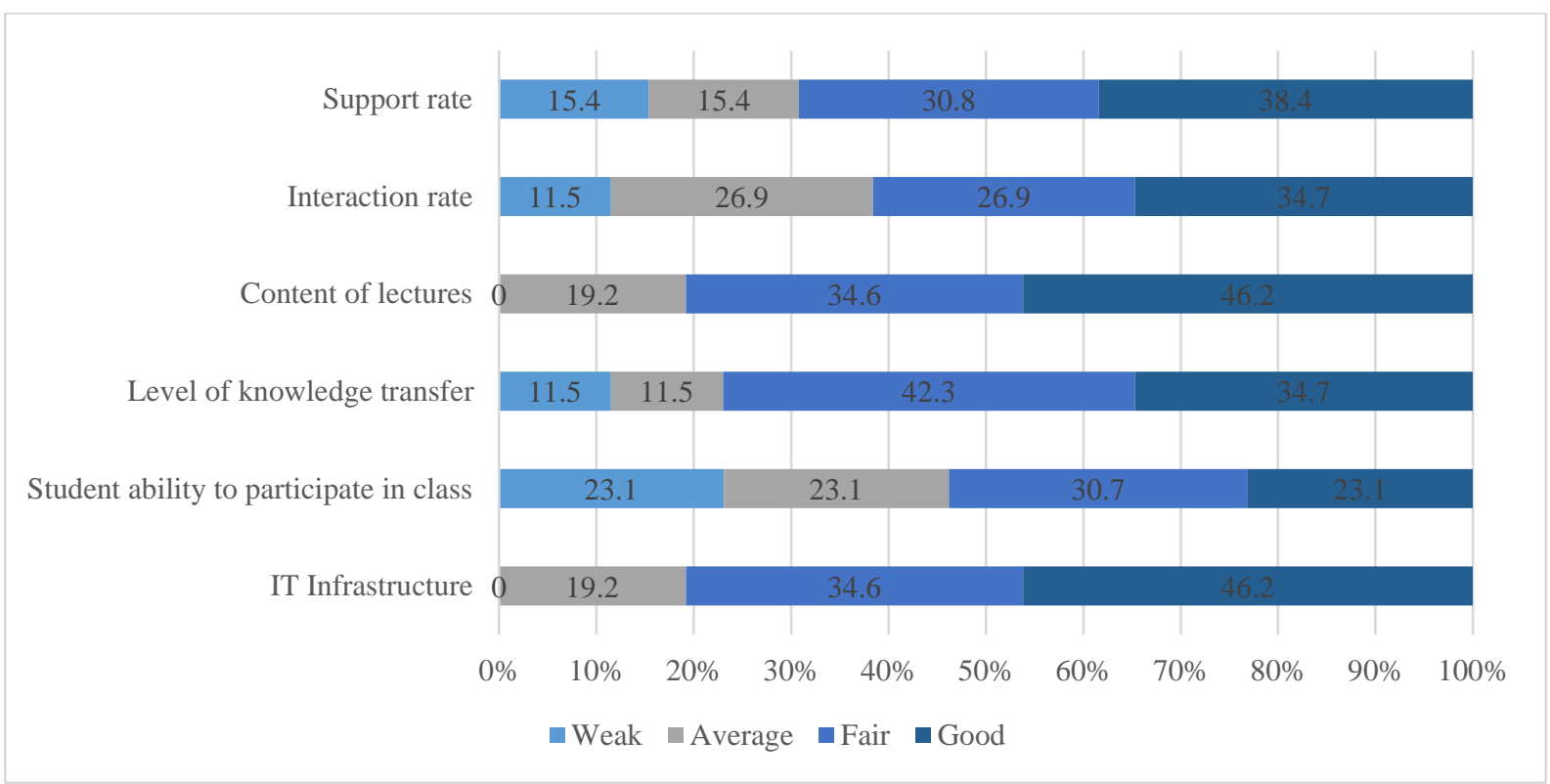

Figure 3. Evaluation of management staff on E-learning

Besides, in another survey, the application of E-learning to distance training was assessed as fair and good $(83.3 \%$ and $16.7 \%$, respectively). However, according to the evaluation of managers, distance training has not yet fully utilized the information technology system and open learning materials at the university to improve the effectiveness of distance training.

The findings show that the application of E-learning in distance training of Can Tho University has initially been effectively implemented and helped ensure the quality of the training and management process, but it has not yet been implemented fully to promote all potentials that the university currently offers. Thus, it is necessary to have specific policies, plans and roadmaps to further promote the advantages of E-learning training in the organization and application in training activities of the university in the coming time.

\subsection{Development policies for E-learning at Can Tho University}

The above analysis and situation show that E-learning training has an increasingly important position and role in life, especially in education and training, contributes greatly to the enhancement of the people's intellectual standards, training human resources and fostering talents. To implement, organize and ensure the quality of E-learning training in the future, this must be the responsibility, the role and the participation of both the political system as well as the State management agencies of education and training.

In light of such requirements, the researchers propose a number of policies to support the development of Elearning in the near future at Can Tho University:

- Raising the awareness of the role and position of E-learning in the current period, from learners to organizations, unions, communities and society to actively participate in the development of E-learning.

- The Ministry of Education and Training should promulgate specific, detailed and effective policies and regulations in order to clearly define the role and position of E-learning and apply E-learning in different training forms, especially in distance training in higher education institutions.

- Encouraging educational institutions, especially higher education institutions, to exploit the advantages of Elearning to organize training, fostering and training courses for granting diplomas or certifications for economic, cultural and social development.

- Investing, supporting and enabling higher education institutions that have implemented E-learning to upgrade and develop online training systems at universities, enhancing open learning materials for online training activities.

- Strengthening the team of staff, lecturers and technical staff in service of E-learning training activities in higher education institutions. And this team must have remuneration policies, and at the same time be regularly trained and fostered to update on the world's advanced knowledge and technology. 
- Developing a set of common criteria for the evaluation and assurance of E-learning training quality, as a basis for higher education institutions to supervise, implement and manage the training process in order to ensure the quality of human resources, to proceed to the granting of common diplomas and forms of training according to law.

- Investing in Hanoi and Ho Chi Minh City Open University as the research and technology transfer centers for E-learning training for the whole system.

- Encouraging units to promote the construction and use of common technologies, programs, lectures, teaching staff, etc. in higher education institutions that have implemented E-learning.

- Developing specific guidelines and policies calling for investments from domestic and foreign investment sources to support the development of the model.

- Enhancing international cooperation to take advantage of the support and supply of financial resources, equipment, technology, lectures, teaching staff, professional techniques from prestigious institutes and schools with E-learning training in the world.

\section{DISCUSSION AND CONCLUSION}

The development of science and technology greatly affects all aspects of life, including education and training. The application of modern technology achievements in the form of E-learning will create more opportunities for people and communities to participate in a learning society, following the inevitable trend of the future.

The study analyzed the current situation of organizing E-learning training at a specific higher education institution, thereby proposing policies to support the development of E-learning in higher education institutions in the future. Effective implementation requires the whole system, especially higher education institutions to consider this as a responsibility and a duty to society and the country. If so, the training activities of higher education institutions will keep up with the general progress of international education.

\section{REFERENCES}

Alonso, F., López, G., Manrique, D. \& Viñes, J.M. (2005). An Instructional Model for Web-based E-learning Education with a Blended Learning Process Approach. British Journal of Educational Technology, 36, 217-235. DOI:10.1111/j.1467-8535.2005.00454.x

Andersson, A. \& Grönlund, Å. (2009). A Conceptual Framework for E-learning in Developing Countries: A Critical Review of Research Challenges. The Electronic Journal of Information Systems in Developing Countries, 38, 1-16. DOI:10.1002/j.1681-4835.2009.tb00271.x

Bui Thanh Giang (2004). Distance learning technologies and E-learning. Post Office Publishing.

Do Xuan Thao \& Le Hai Yen (2008). Building distance learning model by multimedia communication. Journal of Education, 203, 20-23; 12.

Nor Aziah Alias \& Ahmad Marzuki Zainuddin (2005). Innovation for Better Teaching and Learning: Adopting the Learning Management System. Malaysian Online Journal of Instructional Technology, 2(2), $27-40$.

Nguyen Ngoc Trang (2017). Project-based teaching in college information technology training with support of E-learning. Doctoral Thesis in Educational Science, Vietnam Institute of Educational Sciences.

Pham Phuong Tam (2017). Management of distance learning to meet the human resources needs of the Mekong Delta. Hanoi National University Press.

Phan Van Kha \& Pham Phuong Tam (2016). Distance training management model meets the needs of university-level human resources. Journal of Educational Science, Vietnam Academy of Educational Sciences, 134, 13-18.

Prime Minister (2015). Decision No. 1559/QD-TTg dated September 10, 2015 approving the project "Development of distance learning in the period of 2015-2020".

Tran Thanh Dien \& Nguyen Thai Nghe (2017). E-learning models that support teaching and learning. Journal of Science, Can Tho University, Special issue: Information Technology, 103-111. DOI:10.22144/ctu.jsi.2017.014 